Article

\title{
Oral Intake of Royal Jelly Has Protective Effects Against Tyrosine Kinase Inhibitor-Induced Toxicity in Patients with Renal Cell Carcinoma: A Randomized, Double-Blinded, Placebo-Controlled Trial
}

\author{
Kyohei Araki, Yasuyoshi Miyata *, Kojiro Ohba ${ }^{\mathbb{D}}$, Yuichiro Nakamura, Tomohiro Matsuo, \\ Yasushi Mochizuki and Hideki Sakai \\ Department of Urology, Nagasaki University Graduate School of Biomedical Sciences, 1-7-1 Sakamoto, \\ Nagasaki, Nagasaki 852-8501, Japan; k-araki205@cameo.plala.or.jp (K.A.); ohba-k@nagasaki-u.ac.jp (K.O.); \\ yn1238056@yahoo.co.jp (Y.N.); tomozo1228@hotmail.com (T.M.); mochi@nagasaki-u.ac.jp (Y.M.); \\ hsakai@nagasaki-u.ac.jp (H.S.) \\ * Correspondence: yasu-myt@nagasaki-u.ac.jp; Tel.: +81-95-819-7340
}

Received: 5 December 2018; Accepted: 18 December 2018; Published: 20 December 2018

\begin{abstract}
Background: Although tyrosine kinase inhibitors (TKIs) are still recommended as the standard therapy in renal cell carcinoma (RCC), the high frequency of adverse events is a weakness of this therapy. Because royal jelly (RJ) possesses anti-inflammatory and antioxidant properties, we assessed its protective effects on TKI-induced toxicities in RCC patients. Methods: We enrolled 33 patients with advanced RCC who were assigned to start TKI therapy in combination with a randomized, double-blinded, placebo-controlled RJ trial consisting of a placebo group with 17 subjects and an RJ group with 16 subjects. Results: Fatigue and anorexia frequencies in the RJ group were significantly lower than in the placebo group ( $p=0.003$ and 0.015 , respectively). A statistically significant correlation between RJ and fatigue or anorexia was detected in sunitinib-treated patients. The dose reduction- or discontinuation-free periods were significantly longer $(p=0.013)$ in the RJ group than in the placebo group. Furthermore, similar observations were made in sunitinib-treated patients $(p=0.016)$. Conclusions: Our clinical trial showed that RJ exerted protective effects against TKI-induced fatigue and anorexia and lowered TKI dose reduction or discontinuation. Hence, RJ is beneficial for maintaining the quality of life and medication compliance in TKI-treated RCC patients.
\end{abstract}

Keywords: royal jelly; adverse events; tyrosine kinase inhibitors; renal cell carcinoma; double-blinded; randomized clinical trial

\section{Introduction}

Renal cell carcinoma (RCC) is one of the most common urological cancers, and its incidence has continuously increased over the past few decades [1]. Although a nephrectomy is usually performed for organ-confined RCC, additional systematic therapy is the standard treatment strategy in patients with metastatic RCC. Currently, new treatment options including immune check-point inhibitors are being developed; however, a molecularly targeted therapy using tyrosine kinase inhibitors (TKIs) is still the recommended standard therapy for these patients [2-4]. In addition, molecularly targeted therapies are often used as neoadjuvant therapy for cytoreductive nephrectomy [5], and clinical trials of combination therapies including molecularly targeted therapeutics and other anticancer agents are currently in progress [6-8]. On the other hand, a major limitation of molecularly targeted therapies is the relatively high frequency of adverse events (AEs) with occasionally severe effects [9,10]. Therefore, the management of drug-induced AEs is critical for maintaining the quality of life during treatment and continuous therapy in these patients. 
Sunitinib and pazopanib are approved as first-line therapy for patients with RCC, especially in favorable- or intermediate-risk clear cell RCC [2]. In addition, these TKIs are often used in real-world patients with non-clear cell RCC [11]. On the other hand, axitinib and sorafenib are also used in some patients with metastatic RCC [12,13]. Typical AEs linked to these TKIs include various symptoms such as oral mucositis, hand-foot syndrome, hypertension, fatigue, and gastrointestinal events [14-18]. In addition, functional disorders of the kidneys, liver, and thyroid are often associated with TKIs $[14,15,17]$. The occurrence and progression of these AEs are suggested to be mediated by complex mechanisms that involve inflammation, oxidative stress, and the immune system [19-21]. Based on these findings, we hypothesized that controlling these biological factors may suppress TKI-induced adverse events.

Royal jelly (RJ) is secreted by the hypopharyngeal and mandibular glands of worker honeybees of Apis mellifera, and is the exclusive food for the queen honeybee and larvae. The most important biological effects of RJ are its anti-inflammatory and antioxidative activities, and its ability to exert some control over the immune system [22-24]. These RJ-related activities are predicted to be beneficial in the protection against anticancer agent-induced adverse events involving inflammation, oxidative stress, and immune system dysfunction $[25,26]$. In fact, the protective efficacy of RJ against anticancer therapy associated toxic effects, such as oral mucositis, intestinal damage, and nephro- and hepato-toxicities, has been demonstrated in animal models with malignancies [27-30].

Thus, in recent decades, several studies have examined the biological effects of RJ on cancer cell lines and corresponding animal models. However, despite several clinical trials, not many studies have reported the clinical benefits and limitations of RJ administration in cancer patients [31-35]. Specifically, there are no reports about the effects of RJ on the adverse events caused by molecularly targeted therapies in RCC patients. Therefore, the aim of this study was to assess the protective efficacy of RJ against TKI-induced toxicities in patients with RCC.

\section{Methods}

\subsection{Patients}

This study protocol was approved by the Human Ethics Review Committee of Nagasaki University Hospital (Nagasaki, Japan; No. 15102604-2), and it was registered as UMIN000020152. In addition, this trial was conducted according to the Declaration of Helsinki. Patients provided written informed consent to participate in all aspects of the study. Patients with RCC who had been assigned to start TKIs were enrolled by the Nagasaki University Hospital. Eligibility criteria of this trial were age $>20$ years, Eastern Cooperative Oncology Group performance status (ECOG PS) 0 or 1, and no honey allergy.

\subsection{Study Design}

This is a randomized, double-blinded, placebo-controlled clinical trial. Patients were assigned to two groups, namely the placebo and RJ groups, at a ratio of 1:1 using computer-generated random numbers. The patient selection process was performed by independent non-medical staff at our hospital who had no information on the aim of this trial, and the process was also hidden from the patients and urologists who provided treatment until the end of all analyses.

RJ and the placebo were provided by the Yamada Agriculture Center Inc (Okayama, Japan). $\mathrm{RJ}$ and the placebo were prepared as capsules containing $800 \mathrm{mg} \mathrm{RJ}$ and starch, respectively, that share the same taste, smell, size, shape, and color. Capsules were orally administered three times per day for three months.

\subsection{Protocol}

All subjects received medical examinations and were checked for clinical symptoms every two weeks. Blood samples were collected simultaneously every two weeks and subjected to laboratory 
analysis routinely performed in patients treated with TKIs. The initial starting dose of sunitinib, pazopanib, axitinib, and sunitinib was $50 \mathrm{mg} /$ day, $800 \mathrm{mg} /$ day, $10 \mathrm{mg} /$ day, and $800 \mathrm{mg} /$ day, respectively, but if an intolerable $\mathrm{AE}$ was observed, the dose was decreased to $37.5 \mathrm{mg} /$ day, 400-600 mg/day, $5 \mathrm{mg} /$ day, and $400 \mathrm{mg} /$ day, respectively. In addition, for the sunitinib regimen, if the dose reduction was necessary, all affected patients were treated with an alternative every other day [36]. Furthermore, TKI administration was stopped if intolerable AEs persisted or high-grade abnormalities in the blood analysis were observed. The primary outcome was the frequency and severity of AEs caused by TKIs in patients with RCC, and the secondary outcome was the sustained period of the initial TKI regimen.

Toxicities were graded according to the National Cancer Institute Common Terminology Criteria for Adverse Events, version 5.0. In this study, toxicities classified as grade 3 and 4, or identified as the cause for discontinued TKI administration, were judged as severe AEs.

\subsection{Statistical Analyses}

Results are expressed as the mean and standard deviation (SD) for normally distributed data and the median and interquartile range (IQR) for non-normally distributed data. The Student's t-test or Mann-Whitney U test was used to compare continuous variables and Scheffé's method was used for multiple comparisons. The sustained periods of initial dosage were derived from Kaplan-Meier curves, and statistical significance was analyzed using the log-rank test. Values with $p<0.05$ were considered statistically significant. Statistical analyses were carried out using StatView for Windows v.5.0 software (Abacus Concept, Berkeley, CA, USA).

\section{Results}

All subjects of the placebo and RJ group consumed the respective capsules for three months or until disease progression. In addition, we confirmed that the compliance rate was $>95 \%$ in both groups and no patient experienced any side effects including allergy due to the trial capsules.

\subsection{Patient Background}

Thirty-three patients with RCC were enrolled in this study. The pathological features and basic characteristics of our study population at baseline are presented in Table 1.

Table 1. Clinicopathological features and basic characteristics.

\begin{tabular}{|c|c|c|c|c|}
\hline Variables & Entire $(n=33)$ & Placebo $(n=17)$ & Royal Jelly $(n=16)$ & $p$ Value \\
\hline Age & & & & 0.101 \\
\hline Mean $\pm S D$, years & $67.6 \pm 6.6$ & $65.8 \pm 8.8$ & $69.6 \pm 5.9$ & \\
\hline Gender; $n(\%)$ & & & & 0.909 \\
\hline Male/Female & $23 / 10(30.3)$ & $12 / 5(29.4)$ & $11 / 5(31.3)$ & \\
\hline Performance Status & & & & 0.598 \\
\hline $0 / 1$ & $16 / 17(51.5)$ & $9 / 8(47.1)$ & $7 / 9(56.3)$ & \\
\hline Pathological Type & & & & 0.446 \\
\hline Conventional & $29(87.9)$ & $16(94.1)$ & $13(81.3)$ & \\
\hline Fuhrman Grade & & & & 0.425 \\
\hline 1 or $2 / 3$ or 4 & $6 / 27(81.8)$ & $2 / 15(88.2)$ & $4 / 12(75.0)$ & \\
\hline pT stage & & & & 0.201 \\
\hline 1 or $2 / 3$ or 4 & $9 / 24(72.7)$ & 3/14 (82.4) & $6 / 10(62.5)$ & \\
\hline Lymph Node Metastasis & & & & 0.881 \\
\hline Presence & $19(57.6)$ & $10(58.8)$ & $9(56.3)$ & \\
\hline Distant Metastasis & & & & 0.325 \\
\hline Presence & $27(81.8)$ & $15(88.2)$ & $12(75.0)$ & \\
\hline Neo-Adjuvant Setting & & & & 0.965 \\
\hline Yes & $2(6.1)$ & $1(5.9)$ & $1(6.3)$ & \\
\hline
\end{tabular}


Table 1. Cont.

\begin{tabular}{ccccc}
\hline Variables & Entire $(n=33)$ & Placebo $(\boldsymbol{n}=\mathbf{1 7})$ & Royal Jelly $(\boldsymbol{n}=\mathbf{1 6})$ & $\boldsymbol{p}$ Value \\
\hline $\begin{array}{c}\text { Past Therapy Used TKI } \\
\text { Presence }\end{array}$ & $4(12.1)$ & $2(11.8)$ & $2(12.5)$ & 0.948 \\
TKIs & $21(63.6)$ & $11(64.7)$ & $10(62.5)$ & 0.539 \\
Sunitinib & $7(21.2)$ & $3(17.6)$ & $4(25.0)$ & \\
Pazopanib & $4(12.1)$ & $3(17.6)$ & $1(6.3)$ & \\
Axitinib & $1(3.0)$ & $0(0.0)$ & $1(6.3)$ & \\
Sorafenib & & & \\
\hline
\end{tabular}

TKIs = tyrosine kinase inhibitors. $\mathrm{SD}=$ standard deviation.

The statistical analysis indicated that the baseline parameters did not significantly differ between the placebo and the RJ groups. As shown in Table 1, among the 33 patients, 21, 8, and 3 patients were treated with sunitinib, pazopanib, and axitinib, respectively, whereas only one patient was treated with sorafenib. The patients were further divided into two subgroups, namely the sunitinib and the other TKI group, because $63.5 \%$ of the patients were treated with sunitinib. The clinicopathological features and basic characteristics of each subgroup are listed in Table 2.

Table 2. Clinicopathological features and basic characteristics according to used agents.

\begin{tabular}{cccc}
\hline Variables & Placebo & Royal Jelly & $p$ Value \\
\hline Sunitinib & $n=11$ & $n=10$ & \\
Age (mean \pm SD), years & $66.5 \pm 8.3$ & $67.8 \pm 5.8$ & 0.673 \\
Gender; Male/Female, $n(\%)$ & $6 / 5(45.5)$ & $8 / 2(20.0)$ & 0.217 \\
Performance Status; 0/1 & $7 / 4(36.4)$ & $6 / 4(40.0)$ & 0.864 \\
Pathological Type; Conventional & $11(100.0)$ & $8(80.0)$ & 0.297 \\
Fuhrman grade; 2/3+4 & $1 / 10(90.9)$ & $2 / 8(80.0)$ & 0.476 \\
pT stage; 1+2/3+4 & $2 / 9(81.8)$ & $3 / 7(70.0)$ & 0.525 \\
Lymph Node Metastasis; Presence & $7(63.6)$ & $6(60.0)$ & 0.864 \\
Distant Metastasis; Presence & $9(81.8)$ & $8(80.0)$ & 0.916 \\
Neo-Adjuvant Setting; Yes & $1(9.1)$ & $0(0.0)$ & 0.329 \\
Past Therapy Used TKI; Presence & $1(9.1)$ & $0(0.0)$ & 0.329 \\
Others & $n=6$ & $n=6$ & \\
Age (mean \pm SD); years & $64.5 \pm 3.8$ & $72.5 \pm 5.3$ & 0.013 \\
Gender; Male / Female & $6 / 0(0.0)$ & $3 / 3(50.0)$ & 0.182 \\
Performance Status; 0/1 & $2 / 4(66.7)$ & $1 / 5(83.3)$ & 0.505 \\
Pathological Type; Conventional & $5(83.3)$ & $5(83.3)$ & 0.999 \\
Fuhrman grade; 2/3+4 & $1 / 5(83.3)$ & $3 / 3(50.0)$ & 0.221 \\
pT Stage; $1+2 / 3+4$ & $1 / 5(83.3)$ & $2 / 4(66.7)$ & 0.501 \\
LN Metastasis; Presence & $3(50.0)$ & $3(50.0)$ & 0.999 \\
Distant Metastasis; Presence & $6(100.0)$ & $4(66.7)$ & 0.121 \\
Neo-Adjuvant Setting; Yes & $0(0.0)$ & $1(16.7)$ & 0.296 \\
Past Therapy Used TKI; Presence & $1(16.7)$ & $2(33.3)$ & 0.505 \\
\hline
\end{tabular}

In the other TKI group, the mean age of the RJ group was significantly higher $(p=0.013)$ compared to that of the RJ group. However, the remaining parameters did not significantly vary between these two groups.

\subsection{Adverse Events}

In the study population $(n=33)$, the most common AE was hypertension $(n=23 ; 69.7 \%)$ followed by fatigue $(n=20 ; 60.6 \%)$, and anorexia $(n=18 ; 60.0 \%)$ and hand-foot syndrome $(n=18 ; 60.0 \%)$. Furthermore, anorexia $(n=4 ; 12.1 \%)$ was the most common severe adverse event.

As shown in Table 3, the frequencies and severities of fatigue and anorexia were significantly lower in the RJ group than those in the placebo group ( $p=0.003$ and 0.015 , respectively). The digestive symptoms varied similarly, but the difference between the RJ and placebo group was not statistically 
significant $(p=0.077)$. In addition, none of the other symptoms varied significantly, including hypertension. However, when the same analysis was performed separately on the subgroups of patients treated with either sunitinib or other TKIs, such significant differences in fatigue and anorexia differed significantly between the RJ and placebo groups in patients treated with sunitinib $(p=0.040$ and 0.038 , respectively), but not in those treated with other TKIs ( $p=0.065$ and 0.343 , respectively). The frequencies of the remaining symptoms were similar between the two groups regardless of the TKI regimen.

Table 3. Relationships between royal jelly intake and clinical symptoms.

\begin{tabular}{|c|c|c|c|c|c|c|}
\hline Adverse Events & \multicolumn{2}{|c|}{ Entire } & \multicolumn{2}{|c|}{ Sunitinib } & \multicolumn{2}{|c|}{ Others } \\
\hline \multicolumn{7}{|l|}{ Hypertension } \\
\hline Mild & $10(58.8)$ & $12(75.0)$ & $6(54.5)$ & $7(70.0)$ & $4(66.7)$ & $5(83.3)$ \\
\hline Severe & $1(5.9)$ & $0(0.0)$ & $0(0.0)$ & $0(0.0)$ & $1(16.7)$ & $0(0.0)$ \\
\hline$p$ value & \multicolumn{2}{|c|}{0.460} & \multicolumn{2}{|c|}{0.466} & \multicolumn{2}{|c|}{0.574} \\
\hline Mild & $13(76.5)$ & $5(31.3)$ & $9(81.8)$ & $4(40.0)$ & $4(66.7)$ & $1(16.7)$ \\
\hline Severe & $2(11.8)$ & $0(0.0)$ & $1(9.1)$ & $0(0.0)$ & $1(16.7)$ & $0(0.0)$ \\
\hline$p$ value & \multicolumn{2}{|l|}{0.003} & \multicolumn{2}{|c|}{0.040} & \multicolumn{2}{|c|}{0.065} \\
\hline \multicolumn{7}{|l|}{ Anorexia } \\
\hline Nothing & $4(23.5)$ & $11(68.8)$ & $3(27.3)$ & $8(80.0)$ & $1(16.7)$ & $3(50.0)$ \\
\hline Nothing & $6(35.3)$ & $11(68.8)$ & $3(27.3)$ & $7(70.0)$ & $3(50.0)$ & $4(66.7)$ \\
\hline Mild & $8(47.1)$ & $5(31.3)$ & $6(54.5)$ & $3(30.0)$ & $2(33.3)$ & $2(33.3)$ \\
\hline Severe & $3(17.6)$ & $0(0.0)$ & $2(18.2)$ & $0(0.0)$ & $1(16.7)$ & $0(0.0)$ \\
\hline$p$ value & \multicolumn{2}{|l|}{0.077} & \multicolumn{2}{|c|}{0.102} & \multicolumn{2}{|c|}{0.565} \\
\hline \multicolumn{7}{|l|}{ Dysgeusia } \\
\hline Nothing & $7(41.2)$ & $9(56.3)$ & $5(45.5)$ & $5(50.0)$ & $2(33.3)$ & $4(66.7)$ \\
\hline Mild & $9(52.9)$ & $7(43.8)$ & $5(45.5)$ & $5(50.0)$ & $4(66.7)$ & $2(33.3)$ \\
\hline Severe & $1(5.9)$ & $0(0.0)$ & $1(9.1)$ & $0(0.0)$ & $0(0.0)$ & $0(0.0)$ \\
\hline$p$ value & \multicolumn{2}{|l|}{0.479} & \multicolumn{2}{|c|}{0.621} & \multicolumn{2}{|c|}{0.248} \\
\hline \multicolumn{7}{|c|}{ Hand-Foot Syndrome } \\
\hline Nothing & $7(41.2)$ & $8(50.0)$ & $3(27.3)$ & $4(40.0)$ & $4(66.7)$ & $4(66.7)$ \\
\hline$p$ value & 0.353 & & 0.75 & & 0.2 & \\
\hline
\end{tabular}

$\mathrm{RJ}=$ royal jelly.

Table 4 shows the laboratory blood test results in relation to the trial capsule treatment groups. The frequency of patients with normal anemia values was higher in the RJ group (87.5\%) than in the placebo group (58.8\%); however, the difference was not statistically significant $(p=0.162)$. When the same analysis was performed with the data of the sunitinib-treated patients, no significant difference was detected $(p=0.117)$. Overall, none of the laboratory blood test results varied significantly between the placebo and the RJ group (Table 4). 
Table 4. Relationships between royal jelly intake and results of blood examinations.

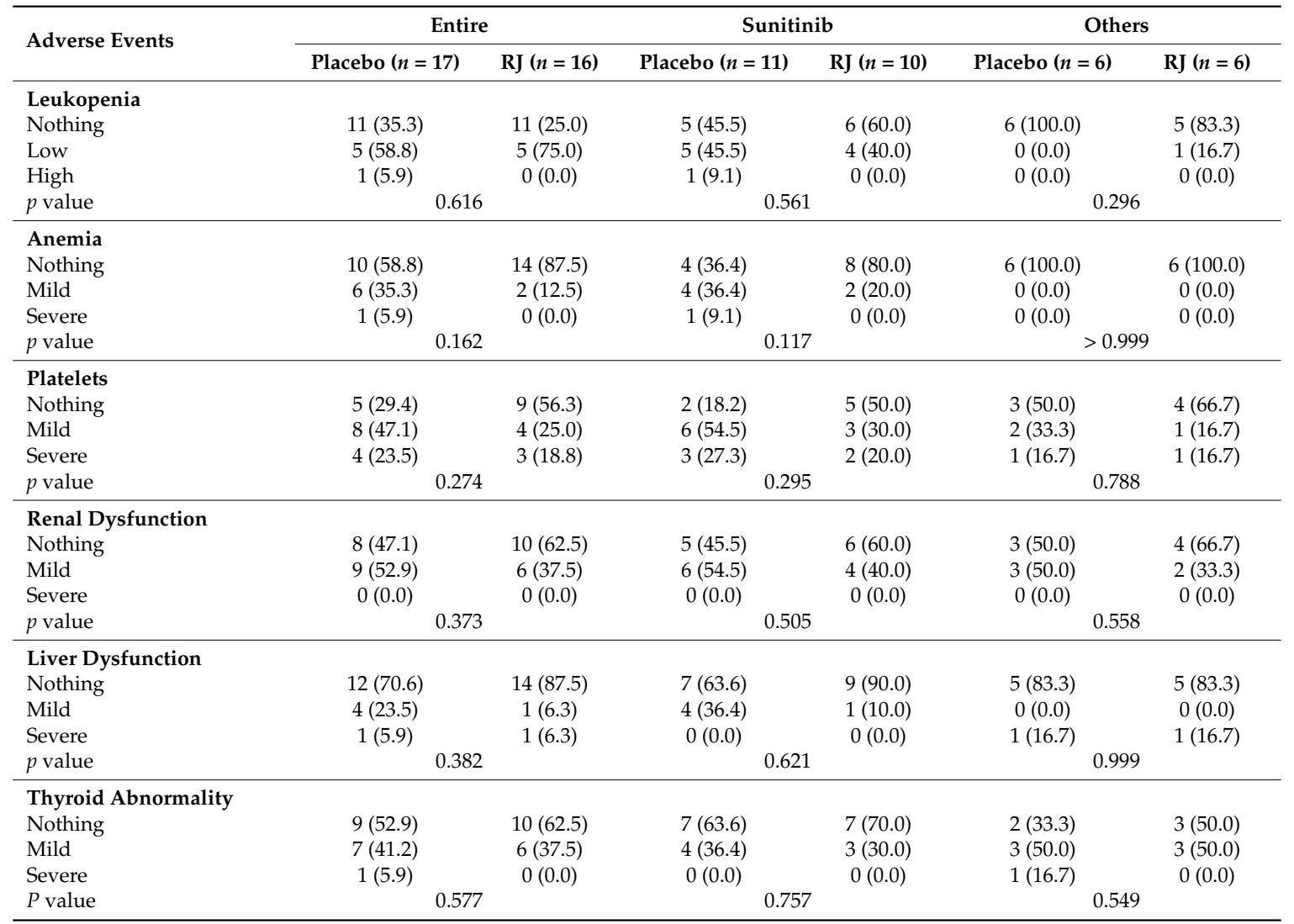

\subsection{Dose Reduction or Discontinuation of Tyrosine Kinase Inhibitors}

In our study population, 23 of the 33 patients (69.7\%) required a dose reduction or discontinuation of the TKI regimen due to severe AEs and disease progression within three months of TKI treatment initiation. The frequency of dose reduction or discontinuation was significantly lower $(p=0.017)$ in the RJ group $(5 / 16=50.0 \%)$ than in the placebo group $(15 / 17=88.2 \%)$. The Kaplan-Meier survival curves for dose-reduction- or discontinuation-free survival rates in the placebo and RJ group are shown in Figure 1A. The free-periods were significantly longer $(p=0.013)$ in the RJ group than in the placebo group. Furthermore, a similar result was observed in patients treated with sunitinib $(p=0.016$; Figure 1B). However, although the dose-reduction- or discontinuation-free survival rates appeared to be better in the RJ group than in the placebo group among patients treated with TKIs other than sunitinib, the difference between these subgroups was not significant ( $p=0.296$; Figure 1C).
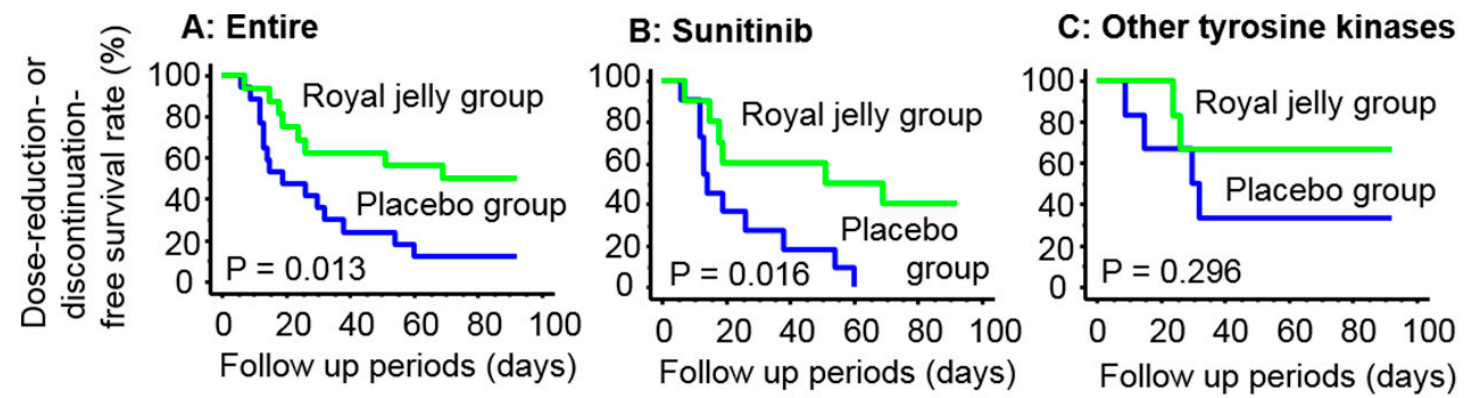

Figure 1. Kaplan-Meier survival curves of the dose-reduction- or discontinuation-free survival rate in the placebo and RJ groups. Dose-reduction- or discontinuation-free survival was better in the RJ group than in the placebo group for patients treated with any TKI (A) and sunitinib (B) $(p=0.127$ and 0.016, respectively). However, this difference was not observed in patients treated with other TKIs (C). 


\section{Discussion}

In this study, we investigated the preventive effects of prophylactic RJ consumption on AEs associated with TKI-induced toxicities because the appropriate management of these AEs is critical for maintaining quality of life in RCC patients treated with TKIs. Various harmful symptoms and abnormal observations are known as adverse events of TKIs [12,14-18]. Among these chemotherapy-induced symptoms, such as oral mucositis, anorexia, digestive symptoms, fatigue, and damage of the kidneys and liver, few have been shown to be suppressed by RJ administration in animal experiments and clinical trials [27-34,37]. In addition, it is known that RJ improves protection against hypertension, hand-foot syndrome, and bone marrow suppression, which are representative adverse events associated with TKIs [38,39]. However, we found that among these harmful symptoms, RJ administration was not significantly associated with the frequency and severity of hypertension, hand-foot syndrome, oral mucositis, dysgeusia, and kidney or liver damage. Importantly, we demonstrated that fatigue and anorexia in the RJ group were significantly mild compared to that in the placebo group. Interestingly, RJ has been shown to exert anti-fatigue effects in an animal experiment that investigated fatigue-related parameters such as serum lactate, serum ammonia, and muscle glycogen after swimming in mice treated with RJ [40]. The study found that these parameters were improved by RJ intake [40]. However, we should note that this fatigue was not induced by anticancer therapies such as TKIs. However, there is a report that processed honey and RJ ameliorated cancer-related fatigue in a double-blinded, randomized clinical trial [33]. Specifically, the visual analogue fatigue scale and fatigue severity score in the test article group (processed honey and RJ for four weeks; $n=26$ ) were significantly lower than those in the control group (pure honey for four weeks; $n=26$ ) [33]. We believe that the present study supports this previous result. However, the previous study had some limitations; for example, the study population included six different types of cancer (breast, gastric, esophageal, colon, rectal, and prostate cancer). Although there was no statistical difference between the composition of the study and control group, the patients had to be treated with four different methods (hormonal therapy, chemotherapy, chemoradiation, and radiotherapy). Furthermore, as discussed by the authors, the short duration of intervention (four weeks) was another limitation [33]. Thus, the present study is the first report on the association between RJ and cancer-related fatigue in RCC patients treated with TKIs. Fatigue is widely recognized as a highly common adverse event in TKI-treated patients with metastatic RCC (sunitinib, 55\%; pazopanib, 27\%; axitinib, 9\%; and sorafenib; $8 \%$ ) [12]. In addition, it was observed that only $4 \%$ of these patients received pharmacologic treatment for fatigue, whereas $72 \%$ of hypertension was treated [12]. Moreover, there are only a few effective treatment options for fatigue caused by TKIs. Hence, our observation that RJ may significantly suppress TKI-induced fatigue is an important finding for TKI-based treatment strategies.

In addition to fatigue, our results demonstrated that RJ suppressed the frequency and severity of anorexia. To our knowledge, this is the first report about the preventive effect of RJ on anorexia in RCC patients. In addition, there is no information on the relationship between RJ and anorexia in patients with malignancies. In general, anorexia in cancer patients is caused by complex interactions involving various factors, such as nausea, constipation, pain, depression, and hypothyroidism [41]. In addition, it is recommended that anorexia treatment should include drugs that target the following conditions: nutritional disorders, muscle catabolism, anemia, and fatigue [42]. Furthermore, it was reported that inflammatory status, oxidative stress, and immunosuppression are important targets for anorexia treatment. From our results, we cannot describe the interactions induced by RJ to exert the preventive effects against anorexia. However, we speculate that there are multiple beneficial effects of RJ on various TKI-induced adverse events including fatigue, digestive symptoms, anemia, and nephroand hepato-toxicities that contribute to this finding, although RJ is not significantly associated with the prevention of these events. Furthermore, RJ has been reported to possess anti-inflammatory and antioxidative activities, and act as a significant regulator of immune conditions caused by anticancer therapies [35]. We agree with the opinion that the clinical management of anorexia requires 
a multidisciplinary and multi-pharmacological approach [42]. As useful information for TKI-treatment management, RJ intake is beneficial to prevent anorexia in cancer patients treated with sunitinib.

Our results showed that RJ had no significant effect on oral mucositis. However, a preliminary study designed as a randomized, single-blinded (physician-blinded) trial showed that prophylactic RJ use led to a significant reduction in head and neck cancer patients. However, the study population was small (the RJ and control groups had seven and six patients, respectively) [32]. On the other hand, other investigators also reported that RJ improved symptoms of oral mucositis and shortened the healing time in 103 patients [31]. However, in these two studies, patients were treated with a combination of chemotherapy and radiotherapy. We believe that $\mathrm{RJ}$ may prevent the oral mucositis caused by chemotherapy and/or radiotherapy, but not by TKIs.

Our results showed that there was no significant relationship between RJ consumption and the blood test results. Several in vivo studies demonstrated RJ administration led to the protection of various organ functions [35]. For example, RJ strongly suppressed clinical and pathological aggravation of the liver, kidneys, and testis in experimental animals treated with cisplatin [29,30,37]. On the other hand, in a human trial, the serum levels of creatinine and urea were significantly increased during the first and second cycle of cisplatin-based chemotherapy in 32 cancer patients, but the increase in kidney function-related parameters was suppressed by RJ administration. However, the nephroprotective activity was not statistically significant [34]. Our results are similar to those reported in this study, and we assume that differences such as species, dosage, and period of RJ treatment as well as physiological characteristics of the kidneys are causes for the different observations in animal models and cancer patients.

Our study design has several limitations that restrict the conclusions about the preventive effects of RJ on AEs caused by TKIs in patients with RCC. First, the trial had a relatively small number of patients in each group. However, we emphasize that this trial is a preliminary study on the RJ consumption by patients with malignancy treated with TKIs. In addition, the number of patients in the present study appears to be relatively similar to that reported in previous clinical trials on RJ administration [32,33]. Second, the RJ capsules were provided by a company that sells supplements made from honey. To ensure that the study is not biased, we performed this trial as a double-blinded, randomized study, and the administration, data collection, and analysis were done by a third party approved by the Human Ethics Review Committee. Therefore, our results were not affected by the company and we did not receive any financial support for the publication of this manuscript. Finally, our study design cannot identify the active substance causing the beneficial functions of RJ. Although RJ contains mostly sugars, lipids, amino acids, and vitamins, 10-hydroxy-2-decenoic acid (10-HDA), royalisin, and apisin are known as major components with pharmacological activities [43-45]. We assume that some of these RJ-specific components may cause the observed effects. Further detailed analyses are necessary to identify the active ingredients.

In conclusion, our results demonstrated that prophylactic RJ intake is effective for the prevention and suppression of sunitinib-induced fatigue and anorexia. In addition, RJ did not affect treatment safety and compliance. Specifically, we found that the risk of TKI dose reduction or discontinuation was significantly lower in the RJ group than in the placebo group. Sunitinib remains a recommended standard agent used singly or in combination with immune therapy, low molecular weight heparin, and vaccines for the treatment of metastatic RCC [6,7]. Therefore, we believe that our results are important to improve the treatment strategies for RCC. On the other hand, we emphasize that further detailed clinical studies with more participants are needed to determine whether RJ intake prevents TKI-induced AEs in cancer patients. 
Author Contributions: Conceptualization: Y.M.; Data Curation: K.O., Y.M.; Formal Analysis: T.M.; Funding acquisition: Y.M.; Investigation: Y.M., K.A., Y.N.; Methodology: K.A., K.O., Y.N.; Supervision: H.S.; Writing-original draft Preparation: K.A., Y.M.; Writing—review and editing: H.S.; All authors agree with the final version of the manuscript. The authors declare that the content of this paper has not been published or submitted for publication elsewhere.

Funding: This study was supported in part by a YAMADA RESEARCH GRANT (to Y.M.).

Acknowledgments: The authors thank Dr. Yuji Sagara for providing technical support.

Conflicts of Interest: The authors declare no conflict of interest.

\section{References}

1. Siegel, R.L.; Miller, K.D.; Jemal, A. Cancer statistics, 2017. CA Cancer J. Clin. 2017, 67, 7-30. [CrossRef] [PubMed]

2. Bedke, J.; Gauler, T.; Grünwald, V.; Hegele, A.; Herrmann, E.; Hinz, S.; Janssen, J.; Schmitz, S.; Schostak, M.; Tesch, H.; et al. Systemic therapy in metastatic renal cell carcinoma. World J. Urol. 2017, 35, 179-188. [CrossRef] [PubMed]

3. Lai, Y.; Zhao, Z.; Zeng, T.; Liang, X.; Chen, D.; Duan, X.; Zeng, G.; Wu, W. Crosstalk between VEGFR and other receptor tyrosine kinases for TKI therapy of metastatic renal cell carcinoma. Cancer Cell Int. 2018, 18, 31. [CrossRef] [PubMed]

4. Zarrabi, K.; Wu, S. Current and emerging therapeutic targets for metastatic renal cell carcinoma. Curr. Oncol. Rep. 2018, 20, 41. [CrossRef] [PubMed]

5. Pooleri, G.K.; Nair, T.B.; Sanjeevan, K.V.; Thomas, A. Neo adjuvant treatment with targeted molecules for renal cell cancer in current clinical practise. Indian J. Surg. Oncol. 2012, 3, 114-119. [CrossRef]

6. Rizzo, M.; Porta, C. Sunitinib in the treatment of renal cell carcinoma: An update on recent evidence. Ther. Adv. Urol. 2017, 9, 195-207. [CrossRef]

7. Wentink, M.Q.; Verheul, H.M.W.; Pal, S.K.; George, S.; Voortman, J.; Danchaivijitr, P.; Adelaiye, R.; Poslinski, D.; Groman, A.; Hutson, A.; et al. Phase I Study of dalteparin in combination with sunitinib in patients with metastatic clear cell renal carcinoma. Clin. Genitourin Cancer 2017. [CrossRef]

8. Atkins, M.B.; Plimack, E.R.; Puzanov, I.; Fishman, M.N.; McDermott, D.F.; Cho, D.C.; Vaishampayan, U.; George, S.; Olencki, T.E.; Tarazi, J.C.; et al. Axitinib in combination with pembrolizumab in patients with advanced renal cell cancer: A non-randomised, open-label, dose-finding, and dose-expansion phase $1 \mathrm{~b}$ trial. Lancet Oncol. 2018, 19, 405-415. [CrossRef]

9. Clarke, J.M.; George, D.J.; Lisi, S.; Salama, A. Immune checkpoint blockade: The new frontier in cancer treatment. Target Oncol. 2018, 13, 1-20. [CrossRef]

10. Guo, J.; Jin, J.; Oya, M.; Uemura, H.; Takahashi, S.; Tatsugami, K.; Rha, S.Y.; Lee, J.L.; Chung, J.; Lim, H.Y.; et al. Safety of pazopanib and sunitinib in treatment-naive patients with metastatic renal cell carcinoma: Asian versus non-Asian subgroup analysis of the COMPARZ trial. J. Hematol. Oncol. 2018, 11, 69. [CrossRef] [PubMed]

11. Fernández-Pello, S.; Hofmann, F.; Tahbaz, R.; Marconi, L.; Lam, T.B.; Albiges, L.; Bensalah, K.; Canfield, S.E.; Dabestani, S.; Giles, R.H.; et al. A systematic review and meta-analysis comparing the effectiveness and adverse effects of different systemic treatments for non-clear cell renal cell carcinoma. Eur. Urol. 2017, 71, 426-436. [CrossRef] [PubMed]

12. Srinivas, S.; Stein, D.; Teltsch, D.Y.; Tao, S.; Cisar, L.; Ramaswamy, K. Real-world chart review study of adverse events management in patients taking tyrosine kinase inhibitors to treat metastatic renal cell carcinoma. J. Oncol. Pharm. Pract. 2018, 24, 574-583. [CrossRef] [PubMed]

13. Sheng, X.; Bi, F.; Ren, X.; Cheng, Y.; Wang, J.; Rosbrook, B.; Jiang, M.; Guo, J. First-line axitinib versus sorafenib in Asian patients with metastatic renal cell carcinoma: Exploratory subgroup analyses of Phase III data. Future Oncol. 2018, in press. [CrossRef] [PubMed]

14. Méndez-Vidal, M.J.; Martínez Ortega, E.; Montesa Pino, A.; Pérez Valderrama, B.; Viciana, R. Management of adverse events of targeted therapies in normal and special patients with metastatic renal cell carcinoma. Cancer Metastasis Rev. 2012, 31, S19-27. [CrossRef] [PubMed] 
15. Escudier, B.; Porta, C.; Bono, P.; Powles, T.; Eisen, T.; Sternberg, C.N.; Gschwend, J.E.; De Giorgi, U.; Parikh, O.; Hawkins, R.; et al. Randomized, controlled, double-blind, cross-over trial assessing treatment preference for pazopanib versus sunitinib in patients with metastatic renal cell carcinoma: PISCES Study. J. Clin. Oncol. 2014, 32, 1412-1418. [CrossRef] [PubMed]

16. Santoni, M.; Conti, A.; De Giorgi, U.; Iacovelli, R.; Pantano, F.; Burattini, L.; Muzzonigro, G.; Berardi, R.; Santini, D.; Cascinu, S. Risk of gastrointestinal events with sorafenib, sunitinib and pazopanib in patients with solid tumors: A systematic review and meta-analysis of clinical trials. Int. J. Cancer 2014, 135, 763-773. [CrossRef]

17. Chrisoulidou, A.; Mandanas, S.; Margaritidou, E.; Mathiopoulou, L.; Boudina, M.; Georgopoulos, K.; Pazaitou-Panayiotou, K. Treatment compliance and severe adverse events limit the use of tyrosine kinase inhibitors in refractory thyroid cancer. Onco. Targets Ther. 2015, 8, 2435-2442.

18. Que, Y.; Liang, Y.; Zhao, J.; Ding, Y.; Peng, R.; Guan, Y.; Zhang, X. Treatment-related adverse effects with pazopanib, sorafenib and sunitinib in patients with advanced soft tissue sarcoma: A pooled analysis. Cancer Manag. Res. 2018, 10, 2141-2150. [CrossRef] [PubMed]

19. Santoni, M.; Rizzo, M.; Burattini, L.; Farfariello, V.; Berardi, R.; Santoni, G.; Carteni, G.; Cascinu, S. Present and future of tyrosine kinase inhibitors in renal cell carcinoma: Analysis of hematologic toxicity. Recent Pat. Antiinfect. Drug Discov. 2012, 7, 104-110. [CrossRef] [PubMed]

20. Gopal, S.; Miller, K.B.; Jaffe, I.Z. Molecular mechanisms for vascular complications of targeted cancer therapies. Clin. Sci. (Lond.) 2016, 130, 1763-1779. [CrossRef] [PubMed]

21. Teppo, H.R.; Soini, Y.; Karihtala, P. Reactive oxygen species-mediated mechanisms of action of targeted cancer therapy. Oxid. Med. Cell. Longev. 2017, 2017, 1485283. [CrossRef] [PubMed]

22. Liu, J.R.; Yang, Y.C.; Shi, L.S.; Peng, C.C. Antioxidant properties of royal jelly associated with larval age and time of harvest. J. Agric. Food Chem. 2008, 56, 11447-11452. [CrossRef] [PubMed]

23. Kolayli, S.; Sahin, H.; Can, Z.; Yildiz, O.; Malkoc, M.; Asadov, A. A member of complementary medicinal food: Anatolian royal jellies, their chemical compositions, and antioxidant properties. J. Evid. Based Complement. Altern. Med. 2016, 21, NP43-NP48. [CrossRef] [PubMed]

24. Yang, Y.C.; Chou, W.M.; Widowati, D.A.; Lin, I.P.; Peng, C.C. 10-hydroxy-2-decenoic acid of royal jelly exhibits bactericide and anti-inflammatory activity in human colon cancer cells. BMC Complement. Altern. Med. 2018, 18, 202. [CrossRef] [PubMed]

25. Hajra, S.; Patra, A.R.; Basu, A.; Bhattacharya, S. Prevention of doxorubicin (DOX)-induced genotoxicity and cardiotoxicity: Effect of plant derived small molecule indole-3-carbinol (I3C) on oxidative stress and inflammation. Biomed. Pharmacother. 2018, 101, 228-243. [CrossRef] [PubMed]

26. Pugazhendhi, A.; Edison, T.N.J.I.; Velmurugan, B.K.; Jacob, J.A.; Karuppusamy, I. Toxicity of Doxorubicin (Dox) to different experimental organ systems. Life Sci. 2018, 200, 26-30. [CrossRef] [PubMed]

27. Kaynar, L.; Cetin, A.; Hacioglu, S.K.; Eser, B.; Koçyigit, İ.; Canöz, Ö.; Tasdemir, A.; Karadag, C.; Kurnaz, F.; Saraymen, R.; et al. Efficacy of royal jelly on methotrexate-induced systemic oxidative stress and damage to small intestine in rats. Afr. J. Tradit. Complement. Altern. Med. 2012, 9, 412-417. [CrossRef] [PubMed]

28. Suemaru, K.; Cui, R.; Li, B.; Watanabe, S.; Okihara, K.; Hashimoto, K.; Yamada, H.; Araki, H. Topical application of royal jelly has a healing effect for 5-fluorouracil-induced experimental oral mucositis in hamsters. Methods Find. Exp. Clin. Pharmacol. 2008, 30, 103-106. [CrossRef]

29. Karadeniz, A.; Simsek, N.; Karakus, E.; Yildirim, S.; Kara, A.; Can, I.; Kisa, F.; Emre, H.; Turkeli, M. Royal jelly modulates oxidative stress and apoptosis in liver and kidneys of rats treated with cisplatin. Oxid. Med. Cell. Longev. 2011, 2011, 981793. [CrossRef]

30. Ibrahim, A.; Eldaim, M.A.; Abdel-Daim, M.M. Nephroprotective effect of bee honey and royal jelly against subchronic cisplatin toxicity in rats. Cytotechnology 2016, 68, 1039-1048. [CrossRef]

31. Erdem, O.; Güngörmüş, Z. The effect of royal jelly on oral mucositis in patients undergoing radiotherapy and chemotherapy. Holist. Nurs. Pract. 2014, 28, 242-246. [CrossRef] [PubMed]

32. Yamauchi, K.; Kogashiwa, Y.; Moro, Y.; Kohno, N. The effect of topical application of royal jelly on chemoradiotherapy-induced mucositis in head and neck cancer: A preliminary study. Int. J. Otolaryngol. 2014, 2014, 974967. [CrossRef]

33. Mofid, B.; Rezaeizadeh, H.; Termos, A.; Rakhsha, A.; Mafi, A.R.; Taheripanah, T.; Ardakani, M.M.; Taghavi, S.M.; Moravveji, S.A.; Kashi, A.S. Effect of processed honey and royal jelly on cancer-related fatigue: A double-blind randomized clinical trial. Electron Phys. 2016, 8, 2475-2482. [CrossRef] [PubMed] 
34. Osama, H.; Abdullah, A.; Gamal, B.; Emad, D.; Sayed, D.; Hussein, E.; Mahfouz, E.; Tharwat, J.; Sayed, S.; Medhat, S.; et al. Effect of honey and royal jelly against cisplatin-induced nephrotoxicity in patients with cancer. J. Am. Coll. Nutr. 2017, 36, 342-346. [CrossRef] [PubMed]

35. Miyata, Y.; Matsuo, T.; Araki, K.; Nakamura, Y.; Sagara, Y.; Ohba, K.; Sakai, H. Anticancer effects of green tea and the underlying molecular mechanisms in bladder cancer. Medicines (Basel) 2018, 5, 87. [CrossRef]

36. Ohba, K.; Miyata, Y.; Watanabe, S.; Hayashi, T.; Kanetake, H.; Kanda, S.; Sakai, H. Clinical significance and predictive value of prostaglandin E2 receptors (EPR) 1-4 in patients with renal cell carcinoma. Anticancer Res. 2011, 31, 597-605.

37. Silici, S.; Ekmekcioglu, O.; Kanbur, M.; Deniz, K. The protective effect of royal jelly against cisplatin-induced renal oxidative stress in rats. World J. Urol. 2011, 29, 127-132. [CrossRef]

38. Yamaura, K.; Tomono, A.; Suwa, E.; Ueno, K. Topical royal jelly alleviates symptoms of pruritus in a murine model of allergic contact dermatitis. Pharmacogn. Mag. 2013, 9, 9-13. [CrossRef]

39. Khazaei, M.; Ansarian, A.; Ghanbari, E. New findings on biological actions and clinical applications of royal jelly: A review. J. Diet. Suppl. 2018, 15, 757-775. [CrossRef]

40. Kamakura, M.; Mitani, N.; Fukuda, T.; Fukushima, M. Antifatigue effect of fresh royal jelly in mice. J. Nutr. Sci. Vitaminol. (Tokyo) 2001, 47, 394-401. [CrossRef]

41. Del Fabbro, E. Current and future care of patients with the cancer anorexia-cachexia syndrome. Am. Soc. Clin. Oncol. Educ. Book 2015, e229-e237. [CrossRef] [PubMed]

42. Macciò, A.; Madeddu, C.; Mantovani, G. Current pharmacotherapy options for cancer anorexia and cachexia. Expert Opin. Pharmacother. 2012, 13, 2453-2472. [CrossRef] [PubMed]

43. Fujiwara, S.; Imai, J.; Fujiwara, M.; Yaeshima, T.; Kawashima, T.; Kobayashi, K. A potent antibacterial protein in royal jelly. Purification and determination of the primary structure of royalisin. J. Biol. Chem. 1990, 265, 11333-11337. [PubMed]

44. Watanabe, K.; Shinmoto, H.; Kobori, M.; Tsushida, T.; Shinohara, K.; Kanaeda, J.; Yonekura, M. Stimulation of cell growth in the U-937 human myeloid cell line by honey royal jelly protein. Cytotechnology 1998, 26, 23-27. [CrossRef] [PubMed]

45. Honda, Y.; Araki, Y.; Hata, T.; Ichihara, K.; Ito, M.; Tanaka, M.; Honda, S. 10-Hydroxy-2-decenoic acid, the major Lipid component of royal jelly, extends the lifespan of caenorhabditis elegans through dietary restriction and target of rapamycin signaling. J. Aging Res. 2015, 2015, 425261. [CrossRef] [PubMed] 